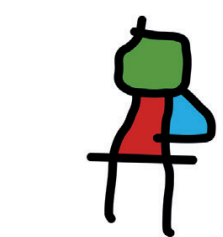

SEICAIP

\section{Allergologia et immunopathologia}

Sociedad Española de Inmunología Clínica, Alergología y Asma Pediátrica

wWw.all-imm.com

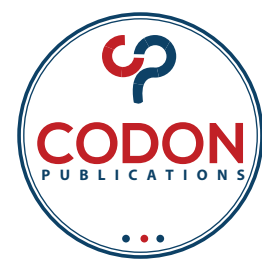

\title{
Microbiological profile in chronic granulomatous disease patients in a single Brazilian primary immunodeficiencies center
}

\author{
Aimée Filippini Bifulco Oliveira ${ }^{a}$, Antonio Carlos Pastorino ${ }^{\mathrm{b} *}$, Mayra de Barros Dorna ${ }^{\mathrm{b}}$, \\ Ana Paula Beltran Moschione Castro ${ }^{\mathrm{b}}$, José Roberto Mendes Pegler ${ }^{\mathrm{b}}$, Beni Morgenstern ${ }^{\mathrm{b}}$, \\ Magda Maria Sales Carneiro-Sampaioc
}

${ }^{a}$ Faculdade de Medicina da, Universidade de São Paulo, São Paulo, Brazil

${ }^{b}$ Pediatric Allergy and Immunology Unit, Instituto da Criança, Hospital das Clinicas da Universidade de São Paulo, São Paulo, Brazil 'Department of Pediatrics, Universidade de São Paulo, São Paulo, Brazil

Received 11 October 2020; Accepted 9 November 2020

Available online 1 July 2021

\section{KEYWORDS \\ abscess; \\ aspergillus; \\ chronic \\ granulomatous \\ disease; \\ mycobacterium, \\ pediatrics; \\ staphylococcal \\ infections}

\begin{abstract}
Background: Chronic granulomatous disease (CGD) is a rare primary immunodeficiency. Infections of the lungs, skin, lymph nodes, and liver are the hallmark of CGD with frequent initial manifestations of the disease. The aim of the present study was to describe the sites of infections and their causative agents in 38 CGD pediatric patients.

Methods: This was a retrospective single-center cohort study comprising CGD patients, and followed for over last 40 years at the Allergy and Immunology Unit of a tertiary hospital in São Paulo, Brazil. Sites of infections and their causative agents were described.

Results: A total of 38 patients were included ( 36 males and 2 females). Median age at the onset of symptoms was 45 days (7 days-7 years) and that at the time of diagnosis was 23 months ( 1 month-12 years); $31.6 \%$ of the parents reported death of relatives during childhood and $21 \%$ ( 8 cases) had another male family member with CDG. The most common infections were pneumonia $(81.6 \%)$, skin infections $(50.0 \%)$, adenitis $(42.1 \%)$, and liver abscess $(23.7 \%)$. In all, 188 cultures were positive $(85.6 \%$ for bacteria and $14.4 \%$ for fungi). The most prevalent bacterial agents were Staphylococcus sp. (12.4\%), Staphylococcus aureus (11.2\%), and Klebsiella pneumoniae (9.3\%). Aspergillus sp. and Candida sp. were $56 \%$ and $22.2 \%$ of the isolated fungi, respectively. Mycobacterium tuberculosis was isolated in $5.6 \%$ and Mycobacterium bovis in $0.9 \%$ (only in 1 patient) of cultures.

Conclusion: Staphylococcus sp., Staphylococcus aureus, and Aspergillus sp. were the most frequent agents in this cohort. M. tuberculosis should be considered in endemic areas. Detection of infectious agents drives to find adequate treatment and benefits the evolution of patients with CGD.

(C) 2021 Codon Publications. Published by Codon Publications.
\end{abstract}

${ }^{*}$ Corresponding authors: Antonio Carlos Pastorino. Pediatric Allergy and Immunology Unit, Instituto da Criança, Hospital das Clinicas da Universidade de São Paulo, São Paulo, Brazil. E-mail address: antonio.pastorino@hc.fm.usp.br 


\section{Introduction}

Chronic granulomatous disease (CGD) is a rare primary immunodeficiency (PID), with an estimated prevalence of around 1:200,000-1:250,000 live births. CGD is caused by gene mutations related to one of the five components of NADPH oxidase enzymatic complex, with about $70 \%$ of the cases with X-linked inheritance. ${ }^{1-3}$

The most frequent clinical manifestations of the disease are recurrent infections. However, inflammatory complications, especially of the gastrointestinal tract, have been described increasingly. ${ }^{2-5}$

Patients with CGD are at high risk of recurrent and severe infections, such as pneumonia, adenitis, osteomyelitis, and abscesses, most commonly affecting the liver and lungs. Catalase-positive bacteria such as Staphylococcus aureus, gram-negative bacteria such as Serratia marcescens, and fungi Aspergillus sp. are the most frequently isolated agents. The implementation of lifelong antimicrobial prophylaxis with sulfamethoxazole-trimethoprim and azole antifungals considerably reduces the morbidity and mortality of these patients. . $^{2,3,6}$

Early diagnosis of infections and the identification of microbial agent are crucial to guide appropriate treatment and prevent serious complications. Patient's general clinical conditions may impact the outcome of hematopoietic stem cell transplantation (HSCT). ${ }^{3,7}$

The aim of the present report is to describe the infectious agents isolated, and the most frequently involved sites of infections in a group of pediatric patients with CGD followed at a single reference center for PID in Brazil.

\section{Method}

A cross-sectional descriptive study of 38 patients followed for the past 40 years (from January 1979 to January 2019) at the Allergy and Immunology Unit of the Hospital das Clínicas da Faculdade de Medicina da Universidade de São Paulo (HC-FMUSP), Brazil. Epidemiological, clinical, and laboratory characteristics, especially about infectious agents and their sites of infections, were obtained from patient's electronic medical records. The Laboratory of Microbiology of HC-FMUSP analyzed samples sent for culture.

Microorganisms isolated from the lungs were obtained thru bronchoalveolar lavage (BAL), sputum, or abscess drainage, and material from liver was obtained from direct puncture or during abscess drainage.

This study was approved by the Ethics Committee of the HC-FMUSP (No. 2.269.479/set 2017). Owing to the characteristics of the study, ethics committee waived the requirement of written informed consent.

\section{Results}

A total of 38 patients were analyzed (36 males and 2 females). Median age at the onset of symptoms was 45 days (ranging from 7 days to 7 years) and median age at the point of diagnosis was 23 months (ranging from 1 month to 12 years); $31.6 \%$ of the patients reported family history of child deaths and $21 \%$ had another male member in the family diagnosed with CGD. Twelve patients belonged to three family groups.

In 18 patients, diagnosis of CGD was based on Nitroblue Tetrazolium (NBT) dye reduction test (13 results were equal to zero and five were below $10 \%$ ), and in 20 patients, diagnosis was by flow cytometry-based Dihydrorhodamine (DHR) oxidation assay (median oxidation index $=1$, ranging from 0 to 16 ).

Infections were the reasons for immunological investigations in $76.3 \%$ of the patients, and family history of child death or CGD was the reason in $15.8 \%$ patients (Figure 1). Only three patients were investigated for other findings: fever without infectious outbreaks in one patient, recurrent thrush in another, and blood in stool in the last one. Pulmonary, skin, or lymph node infections were the most frequent contagions before diagnosis. Less frequently, patients presented with liver abscess, adverse reaction to BCG vaccine, hepatosplenomegaly, osteomyelitis, and cerebral abscess.

All the patients presented infections during follow-up, and pneumonia was the most frequent (81.6\% of patients) illness, followed by skin infections (50.0\%), adenitis (42.1\%), liver abscess (28.9\%), acute otitis media (23.7\%), urinary tract infection $(21.1 \%)$, pulmonary abscess $(15.8 \%)$, and osteomyelitis (10.5\%) (Figure 2).

Microorganisms were isolated from 188 cultures from different sites. Bacterium were identified in $85.6 \%$ of the cultures (24 different species) and fungi in $14.4 \%$ (7 species). The most prevalent bacterium were Staphylococcus sp. (12.4\%), Staphylococcus aureus (11.2\%), Klebsiella pneumoniae (9.3\%), Streptococcus sp. (8.7\%), Escherichia coli (7.5\%), Pseudomonas sp. (6.8\%), Mycobacterium tuberculosis (5.6\%), and Enterobacter cloacae (5.6\%) (Table 1). Among the fungi, Aspergillus sp. was the most frequently isolated pathogen (56.0\%), followed by Candida sp. (22.2\%), and Trichosporon sp. (7.4\%). Other fungi such as Rhodotorula sp., Cladosporium sp., Chrysosporium sp., and Acremonium kiliense were isolated from one culture each (Table 2).

Considering the site of infection, bacteria were identified in all cultures obtained from liver abscesses, staphylococci being the only isolated agent from that site. Bacterium were also the predominant infectious agents isolated in cultures, that is, $93.2 \%$ from the urinary tract, 87.9\% from blood cultures, $86.7 \%$ from skin abscesses, 83.3\% from lymph node puncture cultures, and $76.4 \%$ from the cultures of the lower respiratory tract. Rarely affected sites were the bone marrow, ear, paravertebral region, and parotid gland.

Fungi were isolated in $14.4 \%$ of the positive cultures, Aspergillus being the most frequent one (56\%). The lungs and tracheal secretions were the most frequent sites of isolation of fungi (48.2\%) and Aspergillus corresponded to $46.2 \%$ at this site (Tables 2 and 3 ).

All patients received sulfamethoxazole-trimethoprim prophylaxis after diagnosis, and from 2006 onwards, antifungal prophylaxis with itraconazole or voriconazole was indicated. None of the patients received interferon-gamma, because the drug is not approved in Brazil for treating CGD patients.

During follow-up, 10 of the 38 patients (26.3\%) experienced chronic inflammatory manifestations, especially of 


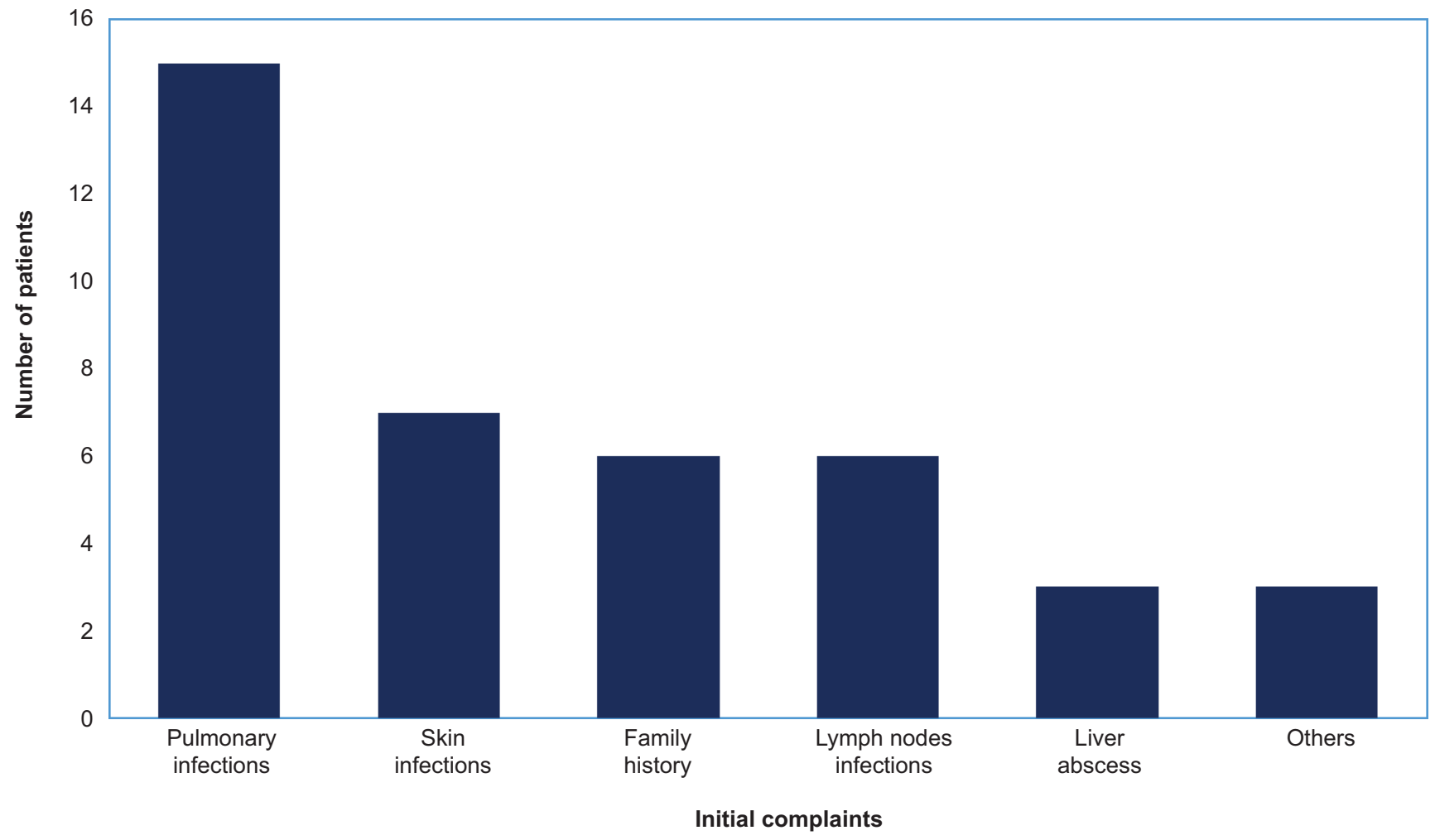

Figure 1 Initial referral complaints of 38 patients with chronic granulomatous disease.

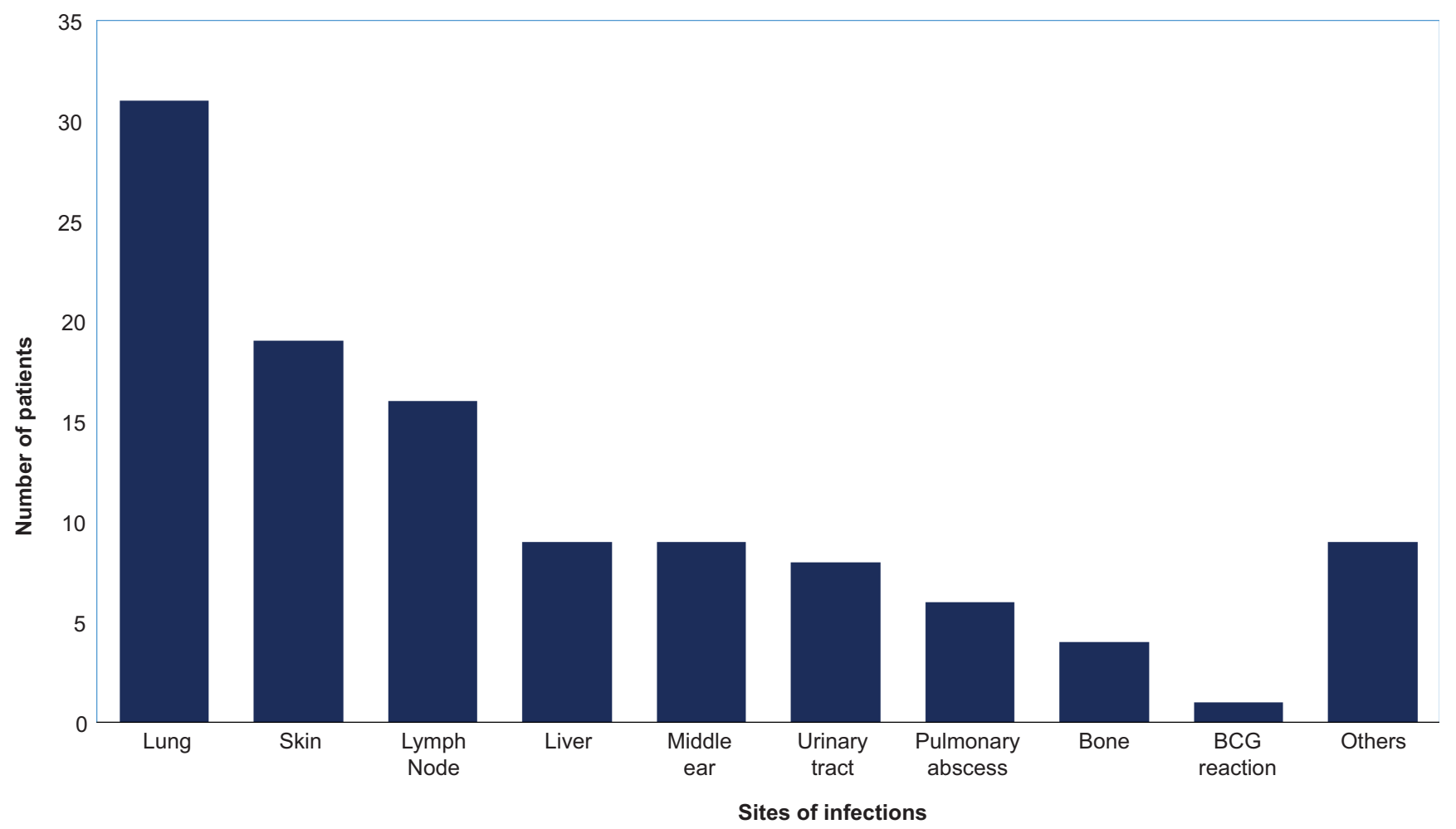

Figure 2 Sites of infection in the evolution of 38 patients with chronic granulomatous disease. 
Table 1 Bacterial infectious agents and isolation sites in 188 positive cultures from 38 chronic granulomatous disease (CGD) patients.

\begin{tabular}{|c|c|c|c|c|}
\hline Agent group & Infectious agent & N (\%) & Isolation site & N (\%) \\
\hline \multirow{62}{*}{$\begin{array}{l}\text { Bacteria } \\
161 \text { Isolations } \\
(85.6 \%)\end{array}$} & \multirow[t]{6}{*}{ Staphylococcus sp. } & \multirow[t]{6}{*}{$20(12.4)$} & Blood & $11(55.0)$ \\
\hline & & & Lung & $2(10.0)$ \\
\hline & & & Liver abscess & $1(5.0)$ \\
\hline & & & Lymph node & $1(5.0)$ \\
\hline & & & Bone marrow & $1(5.0)$ \\
\hline & & & Others & $4(20.0)$ \\
\hline & \multirow{7}{*}{ Staphylococcus aureus } & \multirow{7}{*}{$18(11.2)$} & Liver abscess & $8(44,4)$ \\
\hline & & & Blood & $4(22.20$ \\
\hline & & & Lung & $1(5.6)$ \\
\hline & & & Lymph node & $1(5.6)$ \\
\hline & & & Ear & $1(5.6)$ \\
\hline & & & Urinary tract & $1(5.6)$ \\
\hline & & & Others & $2(11.1)$ \\
\hline & \multirow[t]{3}{*}{ Klebsiella pneumoniae } & \multirow[t]{3}{*}{$15(9.3)$} & Urinary tract & $9(60.0)$ \\
\hline & & & Blood & $5(33.3)$ \\
\hline & & & Lung & $1(6.7)$ \\
\hline & \multirow[t]{5}{*}{ Streptococcus sp. } & \multirow[t]{5}{*}{$14(8.7)$} & Lung & $10(71.4)$ \\
\hline & & & Lymph node & $1(7.1)$ \\
\hline & & & Urinary tract & $1(7.1)$ \\
\hline & & & Bone & $1(7.1)$ \\
\hline & & & Others & $1(7.1)$ \\
\hline & \multirow[t]{4}{*}{ Escherichia coli } & \multirow[t]{4}{*}{$12(7.5)$} & Urinary tract & $8(66.6)$ \\
\hline & & & Skin & $2(16.7)$ \\
\hline & & & Blood & $1(8.3)$ \\
\hline & & & Bone marrow & $1(8.3)$ \\
\hline & \multirow[t]{5}{*}{ Pseudomonas sp. } & \multirow[t]{5}{*}{$11(6.8)$} & Lung & $6(54.5)$ \\
\hline & & & Lymph node & $1(9.1)$ \\
\hline & & & Blood & $1(9.1)$ \\
\hline & & & Urinary tract & $1(9.1)$ \\
\hline & & & Tracheal secretion & $2(8.2)$ \\
\hline & \multirow[t]{3}{*}{ Mycobacterium tuberculosis } & \multirow[t]{3}{*}{$9(5.6)$} & Lung & $6(66.7)$ \\
\hline & & & Lymph node & $2(22.2)$ \\
\hline & & & Bone & $1(11.1)$ \\
\hline & Enterobacter cloacae & $9(5.6)$ & Urinary tract & $5(55.6)$ \\
\hline & & & Blood & $2(22.2)$ \\
\hline & & & Skin & $2(22.2)$ \\
\hline & Enterococcus faecium & $7(4.3)$ & Urinary tract & $3(42.9)$ \\
\hline & & & Skin & $3(42.9)$ \\
\hline & & & Blood & $1(14.3)$ \\
\hline & Burkholderia cepacia complex & $6(3.7)$ & Lung & $2(33.3)$ \\
\hline & & & Tracheal secretion & $2(33.3)$ \\
\hline & & & Lymph node & $1(16.7)$ \\
\hline & & & Skin & $1(16.7)$ \\
\hline & Serratia marcescens & $6(3.7)$ & Skin & $3(50.0)$ \\
\hline & & & Lymph node & $2(33.3)$ \\
\hline & & & Urinary tract & $1(16.7)$ \\
\hline & Enterococcus faecalis & $5(3.1)$ & Urinary tract & $4(80.0)$ \\
\hline & & & Skin & $1(20.0)$ \\
\hline & Corynebacterium sp. & $5(3.1)$ & Lung & $4(80.0)$ \\
\hline & & & Ear & $1(20.0)$ \\
\hline & Stenotrophomonas maltophilia & $4(2.5)$ & Blood & $2(50.0)$ \\
\hline & & & Tracheal secretion & $2(50.0)$ \\
\hline & Morganella morganii & $4(2.5)$ & Urinary tract & $4(100.0)$ \\
\hline & Proteus mirabilis & $4(2.5)$ & Urinary tract & $4(100.0)$ \\
\hline & Haemophilus influenzae & $3(1.9)$ & Lung & $2(66.7)$ \\
\hline & & & Oropharyngeal & $1(33.3)$ \\
\hline & Acinetobacter baumannii complex & $2(1.2)$ & Blood & $2(100.0)$ \\
\hline & Raoultella planticola & $2(1.2)$ & Tracheal secretion & $2(100.0)$ \\
\hline & Mycobacterium bovis & $1(0.6)$ & Lymph node & $1(100.0)$ \\
\hline & Others (Micrococcus luteo, Chryseobacterium sp., & $4(2.5)$ & Ear & $2(50.0)$ \\
\hline & Elizabethkingia meningoseptica, Rothia mucilaginosa & & Cerebrospinal fluid & $1(25.0)$ \\
\hline & & & Skin & $1(25.0)$ \\
\hline
\end{tabular}


Table 2 Fungal agents and isolation sites in 188 positive cultures from 38 chronic granulomatous disease (CGD) patients.

\begin{tabular}{|c|c|c|c|c|}
\hline Agent group & Infectious agent & N (\%) & Isolation site & N (\%) \\
\hline Fungus & Aspergillus sp. & $15(56.0)$ & Lung & $6(40.0)$ \\
\hline \multirow[t]{14}{*}{27 Isolations (14.4\%) } & & & Lymph node & $2(13.3)$ \\
\hline & & & Blood & $2(13.3)$ \\
\hline & & & Skin & $2(13.3)$ \\
\hline & & & Bone & $1(6.7)$ \\
\hline & & & Others & $2(13.3)$ \\
\hline & Candida sp. & $6(22.2)$ & Urinary tract & $3(50.0)$ \\
\hline & & & Blood & $2(33.3$ \\
\hline & & & Lung & $1(16.7)$ \\
\hline & Trichosporon sp. & $2(7.4)$ & Lung & $1(50.0)$ \\
\hline & & & Tracheal secretion & $1(50.0)$ \\
\hline & Cladosporium sp. & $1(3.7)$ & Lung & $1(100.0)$ \\
\hline & Chrysosporium sp. & $1(3.7)$ & Lung & $1(100.0)$ \\
\hline & Rhodotorula sp. & $1(3.7)$ & Lung & $1(100.0)$ \\
\hline & $\begin{array}{l}\text { Acremonium } \\
\text { kiliense }\end{array}$ & $1(3.7)$ & Lung & $1(100.0)$ \\
\hline
\end{tabular}

the gastrointestinal tract $(n=6)$. Most patients used corticosteroids and none of them received tumor necrosis factor (TNF) antagonists.

Death was reported in case of 10 patients ( 5 died due to HSCT complications) and 9 patients lost follow-up or were referred to other centers. Nineteen patients are being followed and six of them have recovered after receiving HSCT.

\section{Discussion}

The current study represents a summary of a 40-year history of infections in children and adolescents with CGD from a tertiary immunodeficiency center in Brazil. Infections of the lung, skin, lymph nodes, and liver are the hallmark of CGD and frequently the initial manifestation of the disease. ${ }^{1}$ Infections caused by S. aureus and Aspergillus, especially in case of complications, could be a warning sign for the diagnosis of CGD. ${ }^{1}$

Although CGD is considered a rare immunodeficiency, we would expect 12 new cases annually in Brazil, where 2.9 million births take place each year. ${ }^{8}$ Even considering the existence of other reference centers in the country, this finding may indicate that CGD is still underdiagnosed. According to the Latin American Society for Immunodeficiencies (LASID), among the 7953 registered patients with PID in 2018, less than 5\% (338 patients) have CGD. ${ }^{9}$

To our knowledge, this report represents the largest CGD cohort ever described by a single Brazilian center and contributes to understanding the infection profile of this group of patients in our country.

This cohort was represented almost entirely by males. This finding agrees with other previous reports, since the most common genetic defect in CGD is located on the $X$ chromosome..$^{2,3}$ Autosomal recessive inheritance is more common in countries with high frequency of consanguinity. ${ }^{10-12}$ In a Turkish study, ${ }^{11}$ consanguinity was reported by 13 of the 24 patients (54\%) and 10 of the 13 patients had an autosomal recessive form of the disease. In our cohort, history of consanguinity in the family was reported only by three patients.

In this study, we observed a high number of relatives with CGD, highlighting the importance of an accurate investigation of family history. This information certainly contributes to earlier diagnosis and implementation of preventive measures, including avoiding BCG vaccination. A study conducted in China ${ }^{13}$ included 159 children diagnosed with CGD; of these, $21 \%$ of patients reported a positive family history of the disease. In another study from a reference center of the United States, ${ }^{14} 40.7 \%$ had other affected family members. In our study, affected families also had a high mortality rate of children without PID diagnosis, indicating that more efforts to improve diagnosis are necessary.

Infections are the most common clinical manifestations in CGD, and strongly related to mortality. ${ }^{1}$ Initial symptoms could occur in very early years of life, and the most commonly affected sites are the lungs and skin. In this cohort, the median age at the onset of symptoms was 45 days and the earliest infection was the impetigo diagnosed at 7 days of age. Early onset of symptoms is frequent in CGD as also observed in the Chinese study that reported the earliest clinical manifestation at the age of 5 days. ${ }^{13}$

Among our patients, the most frequent initial manifestation was pulmonary infection, which was generally difficult to treat, requiring multiple antibiotic regimens, sometimes evolving to abscesses. The skin and lymph node infections, including abscesses, were also an early manifestation of the disease. These findings were similar to those from larger studies conducted in the United States, ${ }^{14,15}$ Europe, ${ }^{12,16}$ and other countries. ${ }^{11-13,17}$ During follow-up, the lungs, skin and lymph nodes remained the most frequent sites of infections in our cohort, which is in agreement with the data obtained from our previous study and from a retrospective study conducted in Latin America. ${ }^{8,18}$ In fact, the lungs are consistently described as the most frequent site of agents' detection in CGD. ${ }^{13,16,18-20}$ 
Table 3 Infectious agents according to the isolation site in 188 positive cultures.

\begin{tabular}{|c|c|c|}
\hline Isolation site & Infectious agents & N (\%) \\
\hline \multirow{18}{*}{$\begin{array}{l}\text { Lung and } \\
\text { tracheal } \\
\text { secretion } \\
(\mathrm{N}=55)\end{array}$} & Streptococcus sp. & $10(18.2)$ \\
\hline & Pseudomonas sp. & $8(14.5)$ \\
\hline & Mycobacterium tuberculosis & $6(10.9)$ \\
\hline & Corynebacterium sp. & $4(7.3)$ \\
\hline & Burkholderia cepacia complex & $4(7.3)$ \\
\hline & Staphylococcus sp. & $2(3.6)$ \\
\hline & Stenotrophomonas maltophilia & $2(3.6)$ \\
\hline & Haemophilus influenzae & $2(3.6)$ \\
\hline & Raoultella planticola & $2(3.6)$ \\
\hline & Staphylococcus aureus & $1(1.8)$ \\
\hline & Klebsiella pneumoniae & $1(1.8)$ \\
\hline & Aspergillus sp. & $6(10.9)$ \\
\hline & Trichosporon sp. & $2(3.6)$ \\
\hline & Candida sp. & $1(1.8)$ \\
\hline & Cladosporium sp. & $1(1.8)$ \\
\hline & Chrysosporium sp. & $1(1.8)$ \\
\hline & Rhodotorula sp. & $1(1.8)$ \\
\hline & Acremonium kiliense & $1(1.8)$ \\
\hline \multirow{12}{*}{$\begin{array}{l}\text { Urinary } \\
\text { tract } \\
\qquad(\mathrm{N}=44)\end{array}$} & Klebsiella pneumoniae & $9(20.5)$ \\
\hline & Escherichia coli & $8(18.2)$ \\
\hline & Enterobacter cloacae & $5(11.4)$ \\
\hline & Morganella morganii & $4(9.1)$ \\
\hline & Proteus mirabilis & $4(9.1)$ \\
\hline & Enterococcus faecalis & $4(9.1)$ \\
\hline & Enterococcus faecium & $3(6.8)$ \\
\hline & Staphylococcus aureus & $1(1.3)$ \\
\hline & Pseudomonas sp. & $1(1.3)$ \\
\hline & Serratia marcescens & $1(1.3)$ \\
\hline & Streptococcus sp. & $1(1.3)$ \\
\hline & Candida sp. & $3(6.8)$ \\
\hline \multirow{12}{*}{$\begin{array}{l}\text { Blood } \\
\qquad(N=33)\end{array}$} & Staphylococcus sp. & $11(33.3)$ \\
\hline & Klebsiella pneumoniae & $5(15.2)$ \\
\hline & Staphylococcus aureus & $4(12.1)$ \\
\hline & Stenotrophomonas maltophilia & $2(6.1)$ \\
\hline & Enterobacter cloacae & $2(6.1)$ \\
\hline & Acinetobacter baumannii & $2(6.1)$ \\
\hline & complex & $1(3.0)$ \\
\hline & Pseudomonas sp. & $1(3.0)$ \\
\hline & Escherichia coli & $1(3.0)$ \\
\hline & Enterococcus faecalis & \\
\hline & Aspergillus sp. & $2(6.1)$ \\
\hline & Candida sp. & $2(6.1)$ \\
\hline \multirow{8}{*}{$\begin{array}{l}\text { Skin } \\
\qquad(N=15)\end{array}$} & Enterococcus faecium & $3(20.0)$ \\
\hline & Serratia marcescens & $3(20.0)$ \\
\hline & Enterobacter cloacae & $2(8.3)$ \\
\hline & Escherichia coli & $2(8.3)$ \\
\hline & Enterococcus faecalis & $1(8.3)$ \\
\hline & Rothia mucilaginosa & $1(8.3)$ \\
\hline & Burkholderia cepacia complex & $1(8.3)$ \\
\hline & Aspergillus sp. & $2(16.7)$ \\
\hline \multirow{5}{*}{$\begin{array}{l}\text { Lymph node } \\
\qquad(\mathrm{N}=12)\end{array}$} & Mycobacterium tuberculosis & $2(16.7)$ \\
\hline & Serratia marcescens & $2(16.7)$ \\
\hline & Staphylococcus aureus & $1(8.3)$ \\
\hline & Staphylococcus sp. & $1(8.3)$ \\
\hline & Streptococcus sp. & $\begin{array}{c}1(8.3) \\
\text { (continues }\end{array}$ \\
\hline
\end{tabular}

Table 3 Continued

\begin{tabular}{cll}
\hline Isolation site & Infectious agents & $\mathrm{N}(\%)$ \\
\hline & Pseudomonas sp. & $1(8.3)$ \\
& Burkholderia cepacia complex & $1(8.3)$ \\
& Mycobacterium bovis & $1(8.3)$ \\
& Aspergillus sp. & $2(16.7)$ \\
Liver & Staphylococcus aureus & $8(88.9)$ \\
abscess & Staphylococcus sp. & $1(11.1)$ \\
$(\mathrm{N}=9)$ & & \\
Others & Staphylococcus sp. & $5(25.0)$ \\
$(\mathrm{N}=20)$ & Staphylococcus aureus & $3(15.0)$ \\
& Streptococcus sp. & $2(10.0)$ \\
& Corynebacterium sp. & $1(5.0)$ \\
& Escherichia coli & $1(5.0)$ \\
& Elizabethkingia meningoseptica & $1(5.0)$ \\
& Mycobacterium tuberculosis & $1(5.0)$ \\
& Haemophilus influenzae & $1(5.0)$ \\
& Micrococcus luteus & $1(5.0)$ \\
& Chryseobacterium sp. & $1(5.0)$ \\
& Aspergillus sp. & $3(15.0)$ \\
\hline
\end{tabular}

In our study, microorganisms were identified in 188 cultures from different sites. One-third of the specimens were obtained from the lower respiratory tract by BAL, sputum, or drainage of pulmonary abscesses. The urinary tract was the second most frequent site of microorganism's isolation, often obtained in the screening for fever without localizing signs in a patient with PID. Aerobic and anaerobic blood cultures were part of the investigations of PID patients with clinical findings of severity or in need of hospitalization and treatment with parenteral antibiotics. Identification of causative agents and their susceptibility profiles were of great importance to guide treatment and, in this context, invasive procedures may be necessary.

In agreement with previous studies, Staphylococcus and Aspergillus were the most frequently isolated infectious agents. ${ }^{14,16,18,21,22}$ In fact, the susceptibility to Staphylococcus aureus infection is a hallmark of CGD and is due to defect of reactive oxygen species (ROS) generation in phagocytes, essential to eliminate pathogens. ${ }^{23}$ Staphylococcus sp., previously considered simple commensal bacteria, are today grouped under the name of coagulase-negative staphylococcus (CoNS) and recognized for containing numerous virulence factors, especially important in nosocomial infections. ${ }^{24}$

Aspergillus is a common cause of invasive infections in CGD and even after the implementation of fungal prophylaxis it remains an important cause of complications and high morbidity and mortality rates. ${ }^{25,26}$ In fact, CGD is the most common PID associated with invasive aspergillosis. ${ }^{27}$ In our cohort, we could not differentiate among Aspergillus $s p$. responsible for invasive infections, but in literature Aspergillus fumigatus and Aspergillus nidulans are the most frequently related agents. ${ }^{25,26}$

In our patients, Mycobacterium tuberculosis was isolated exclusively from the specimens of the lungs and lymph nodes. This finding is not surprising, since tuberculosis is endemic in Brazil. ${ }^{28}$ On the other hand, Mycobacterium bovis was isolated only in one culture. In 
fact, in spite of the administration of BCG vaccine to many patients, adverse events were uncommon. This finding differs from a multicenter study conducted in Latin America, ${ }^{18}$ where adverse reaction to BCG vaccine was the first clinical manifestation in many patients. A study comprising CGD patients that presented reaction to BCG found that $28 \%$ of the patients presented disseminated disease, emphasizing the risks related to administration of BCG vaccine. ${ }^{20}$

Pseudomonas sp., Serratia marcescens, and Burkholderiaceae were less frequently isolated. Together with Staphylococcus and Aspergillus, these infectious agents were among the most commonly reported pathogens in CGD. ${ }^{4}$ Different from other studies, Nocardia sp. and Salmonella sp. were not isolated from our cohort. . $^{13,14,16,18,21}$

Unusual and opportunistic bacteria and fungi were also isolated in our cohort. Unusual fungi were identified mainly in the lungs. These fungi have already been described in other cases of CGD and are responsible for invasive infections. In fact, the prevalence of invasive fungal infection is high among patients with CGD, ranging from $20 \%$ to $40 \%{ }^{29}$ Unexpectedly, Candida sp. was the second most prevalent isolated fungus in our study. This finding was probably related to long-term hospitalization with the use of broad-spectrum antibiotics and invasive devices, and not directly related to the immunological defects of CGD. ${ }^{29}$

Considering the sites where the microorganisms were isolated, some important observations were made. Not only the lungs were the most frequent site where the pathogens were detected but it was also the organ where the greatest variability of microorganisms was found, including opportunistic fungi. Blood cultures represent an important tool to detect microorganisms, especially if there is sepsis. As we could see in our study, we could even detect potentially pathogenic bacteria such as Staphylococcus sp. in the bloodstream.

Liver abscesses are frequent in patients with CGD. In the larger US cohort, liver abscesses occurred in onethird of the patients, and S. aureus was the predominant microorganism isolated. ${ }^{21,30}$ In our cohort, the only microorganisms isolated from liver abscesses drainage were Staphylococcus, almost all of them being $S$. aureus. In fact, in our study liver abscesses were the source of almost a quarter of all isolated Staphylococcus sp.

This study contributes to the understanding of infectious profile of patients with CGD in a Latin American country. The number of patients included seems representative, considering that this is a single-center study, but it also has limitations. As a long-term retrospective study, changes in patient approach, awareness of the disease, new comorbidities, and availability and accuracy of diagnostic methods certainly occurred. In the past, initial treatment was empiric, based on the most common agents reported in literature, so cultures were obtained only from patients having severe or complicated infections. CGD is a rare PID and infections are the most frequent clinical manifestations. Knowledge of local microbiological profile is essential for adequate treatment and favorable outcome of patients with CGD.

\section{Impact statement}

This study contributes to the understanding of the infectious profile of patients with CGD in a Latin American country. This single-center study included a representative number of Brazilian patients with CGD. The initial treatment should be based on the most common agents reported in literature, but the active search of pathogens could guide to treatment of this rare PID.

\section{Conflict of interest}

There was no conflict of interest on the part of authors.

\section{Funding}

There was no funding for the study.

\section{References}

1. Holland SM. Chronic granulomatous disease. Hematol Oncol Clin North Am. 2013;27(1): 89-99. https://doi.org/10.1016/j. hoc.2012.11.002

2. Chiriaco M, Salfa I, Di Matteo G, Rossi P, Finocchi A. Chronic granulomatous disease: Clinical, molecular, and therapeutic aspects. Pediatr Allergy Immunol. 2016;27(3):242-53. https:// doi.org/10.1111/pai.12527

3. Arnold DE, Heimall JR. A review of chronic granulomatous disease. Adv Ther. 2017;34(12):2543-57. https://doi.org/10.1007/ s12325-017-0636-2

4. Magnani A, Brosselin $P$, Beauté $J$, de Vergnes $N$, Mouy $R$, Debré $M$, et al. Inflammatory manifestations in a single-center cohort of patients with chronic granulomatous disease. J Allergy Clin Immunol. 2014;134(3):655-62.e8. https://doi. org/10.1016/j.jaci.2014.04.014

5. Gennery A. Recent advances in understanding and treating chronic granulomatous disease. F1000 Res. 2017;6:1427. https://doi.org/10.12688/f1000research.11789.1

6. Gallin JI, Alling DW, Malech HL, Wesley R, Koziol D, Marciano B, et al. Itraconazole to prevent fungal infections in chronic granulomatous disease. N Engl J Med. 2003;348(24):2416-22. https://doi.org/10.1056/NEJMoa021931

7. Connelly JA, Marsh R, Parikh S, Talano JA. Allogeneic hematopoietic cell transplantation for chronic granulomatous disease: Controversies and state of the art. J Pediatric Infect Dis Soc. 2018;7(Suppl 1):S31-9. https://doi.org/10.1093/jpids/ piy015

8. Ministério da Saúde. Portal da Saúde. Sistema de Informações sobre Nascidos Vivos ( SINASC). Live births in Brazil 2019 [Internet]. Available from: http://tabnet.datasus.gov.br/cgi/ tabcgi.exe?sinasc/cnv/nvuf.def Accessed December 21, 2020.

9. Latin American Society for Immunodeficiencies (LASID). Statistic Register of PID cases [Internet]. Available from http://www.bragid.org.br/_download/registro/estatisticas_2018_08.pdf. Accessed December 21, 2020.

10. Kutukculer N, Aykut A, Karaca NE, Durmaz A, Aksu G, Genel F, et al. Chronic granulomatous disease: Two decades of experience from a pediatric immunology unit in a country with high rate of consanguineous marriages. Scand J Immunol. 2019;89(2):e12737. https://doi.org/10.1111/sji.12737

11. Fattahi F, Badalzadeh $M$, Sedighipour L, Movahedi $M$, Fazlollahi MR, Mansouri SD, et al. Inheritance pattern and clinical aspects of 93 Iranian patients with chronic granulomatous disease. J Clin Immunol. 2011;31(5):792-801. https://doi. org/10.1007/s10875-011-9567-x

12. Al-Zadjali S, Al-Tamemi S, Elnour I, AlKindi S, Lapoumeroulie C, Al-Maamari S, et al. Clinical and molecular findings of chronic 
granulomatous disease in Oman: Family studies. Clin Genet. 2015;87(2):185-9. https://doi.org/10.1111/cge.12351

13. Gao LW, Yin QQ, Tong YJ, Gui JG, Liu XY, Feng XL, et al. Clinical and genetic characteristics of Chinese pediatric patients with chronic granulomatous disease. Pediatr Allergy Immunol. 2019;30(3):378-86. https://doi.org/10.1111/ pai.13033

14. Bortoletto P, Lyman K, Camacho A, Fricchione M, Khanolkar A, Katz BZ. Chronic granulomatous disease, a large, single-center US experience. Pediatr Infect Dis J. 2015;34(10):1110-4. https://doi.org/10.1097/INF.0000000000000840

15. Winkelstein JA, Marino MC, Johnston RB Jr, Boyle J, Curnutte J, Gallin JI, et al. Chronic granulomatous disease. Report on a national registry of 368 patients. Medicine (Baltimore). 2000;79(3):155-69. https://doi org/10.1097/00005792-200005000-00003

16. van den Berg JM, van Koppen E, Ahlin A, Belohradsky BH, Bernatowska E, Corbeel L, et al. Chronic granulomatous disease: The European experience. PLoS ONE. 2009;4(4):e5234. https://doi.org/10.1371/journal.pone.0005234

17. Wu J, Wang WF, Zhang YD, Chen TX. Clinical features and genetic analysis of 48 patients with chronic granulomatous disease in a single center study from Shanghai, China (20052015): New studies and a literature review. J Immunol Res. 2017;2017:8745254. https://doi.org/10.1155/2017/8745254

18. de Oliveira-Junior EB, Zurro NB, Prando C, Cabral-Marques O, Pereira PV, Schimke LF, et al. Clinical and genotypic spectrum of chronic granulomatous disease in 71 Latin American patients: First report from the LASID registry. Pediatr Blood Cancer. 2015;62(12):2101-7. https://doi.org/10.1002/pbc.25674

19. Martire B, Rondelli R, Soresina A, Pignata C, Broccoletti T, Finocchi A, et al. Clinical features, long-term follow-up and outcome of a large cohort of patients with chronic granulomatous disease: An Italian multicenter study. Clin Immunol. 2008;126(2):155-64. https://doi.org/10.1016/j. clim.2007.09.008

20. Conti F, Lugo-Reyes SO, Blancas Galicia L, He J, Aksu G, Borges de Oliveira E Jr, et al. Mycobacterial disease in patients with chronic granulomatous disease: A retrospective analysis of 71 cases. J Allergy Clin Immunol. 2016;138(1):241-8. e3. https:// doi.org/10.1016/j.jaci.2015.11.041
21. Rawat A, Vignesh P, Sharma A, Shandilya JK, Sharma M, Suri D, et al. Infection profile in chronic granulomatous disease: $A$ 23-year experience from a tertiary care center in north India. J Clin Immunol. 2017;37(3):319-28. https://doi.org/10.1007/ s10875-017-0382-x

22. Marciano BE, Spalding C, Fitzgerald A, Mann D, Brown T, Osgood S, et al. Common severe infections in chronic granulomatous disease. Clin Infect Dis. 2015;60(8):1176-83. https:// doi.org/10.1093/cid/ciu1154

23. Buvelot H, Posfay-Barbe KM, Linder P, Schrenzel J, Krause KH. Staphylococcus aureus, phagocyte NADPH oxidase and chronic granulomatous disease. FEMS Microbiol Rev. 2017;41(2):139-57. https://doi.org/10.1093/femsre/fuw042

24. Argemi X, Hansmann Y, Prola K, Prévost G. Coagulase-negative staphylococci pathogenomics. Int J Mol Sci. 2019;20(5):1215. https://doi.org/10.3390/ijms20051215

25. King J, Henriet SSV, Warris A. Aspergillosis in chronic granulomatous disease. J Fungi (Basel). 2016;2(2):pii: E15. https://doi. org/10.3390/jof2020015

26. Bennett N, Maglione PJ, Wright BL, Zerbe C. Infectious complications in patients with chronic granulomatous disease. $\mathrm{J}$ Pediatric Infect Dis Soc. 2018;7(Suppl 1):S12-S17. https://doi. org/10.1093/jpids/piy013

27. Blumental S, Mouy R, Mahlaoui N, Bougnoux ME, Debré $M$, Beauté J, et al. Invasive mold infections in chronic granulomatous disease: A 25-year retrospective survey. Clin Infect Dis. 2011;53(12):e159-69. https://doi.org/10.1093/cid/cir731

28. Ministério Da Saúde. Manual de recomendações para o controle da tuberculose no Brasil, 2 ${ }^{\mathrm{a}}$ edição atualizada. 2019. Available from: http:bvsms.saude.gov.brbvs/bvs/publicacoes/ manual_recomendações_controle_tuberculose_brasil_2_ ed.pdf. Accessed April 28, 2020.

29. Falcone EL, Holland SM. Invasive fungal infection in chronic granulomatous disease: Insights into pathogenesis and management. Curr Opin Infect Dis. 2012;25(6):658-69. https://doi. org/10.1097/QCO.0b013e328358b0a4

30. Lublin M, Bartlett DL, Danforth DN, Kauffman H, Gallin JI, Malech HL, et al. Hepatic abscess in patients with chronic granulomatous disease. Ann Surg. 2002;235(3):383-91. https:// doi.org/10.1097/00000658-200203000-00010 